\title{
THE STRUCTURAL EVOLUTION OF AN ORTHOGNEISS-FOLD WITHIN THE REITZENHAINER ROTGNEISSTRUKTUR (ERZGEBIRGE MTS., GDR)
}

\author{
V. DAMM $\dagger$ K. FELDMANN, A. FRISCHBUTTER, $\dagger$ \\ W. KLEINSTEUBER and $\mathrm{K}$. WALTHER \\ Laboratory of Neutron Physics, Joint Institute for Nuclear Research, Dubna, \\ USSR \\ †Central Institute of the Physics of the Earth, Academy of Sciences of GDR, \\ DDR-1500 Potsdam, GDR
}

(Received 1 July 1988)

\begin{abstract}
The crystallographic preferred orientations of quartz in gneiss taken from different spots of a recumbent fold structure in the Erzgebirge Mts. (southern GDR) are studied by means of neutron time-of-flight diffraction. A single component texture has been found for all specimens, with quartz $c$-axes parallel to the tectonic $a$-direction. The variations in texture sharpness are related to different deformation conditions of the samples. A fabric rotation of $30^{\circ}$ has been found from the limb to the crest of the fold on the basis of $(10 \overline{1} 0)$ and $(11 \overline{2} 0)$ pole figures. The basal pole figures of quartz derived from an ODF analysis compared well with optical U-stage measurements. The determined fabrics are discussed taking into account model calculations of experimentally deformed quartzites and geological informations.
\end{abstract}

KEY WORDS Orthogneiss, Quartz, Petro-fabric analysis, ODF analysis, Neutron diffraction, TOF-measurement.

\section{INTRODUCTION}

Petrofabric analysis contains information about the deformation history of the sample. Comparing the orientation distribution of the grains in naturally deformed rocks with the texture of experimentally deformed material and computer simulations of the deformation process, the data may be used to estimate not only the conditions of temperature, pressure, stress and strain but also the deformation mechanisms which were active. The grain orientations with respect to the sample are completely described by the orientation distribution function (ODF) which can be determined by single orientation measurements or by pole figure inversion. A representative average of the rock fabric can be obtained by neutron diffraction on large samples.

In this paper the partial texture of quartz in four gneisses from selected points of a fold structure in the Central Erzgebirge is studied. The investigations continue the work of Drechsler et al. (1988). All pole figure measurements were carried out by neutron time-of-flight (TOF) diffraction at the pulsed reactor 
IBR-2 in Dubna (Feldmann, 1986). The reproduction of the ODFs from experimental pole figures as well as the determination of inverse pole figures and the comparision with recalculated pole figures have been done by spherical harmonics analysis (Bunge, 1982).

\section{GEOLOGICAL SETTING}

In the present paper the quartz fabric evolution is investigated within a fold structure of pre-Variscan orthogneisses. The folded rock is the so called "Innerer Rotgneis" which forms the core of the "Reitzenhainer Rotgneisstruktur," situated SW of the Floeha-syncline, within the Erzgebirge-anticlinorium (GDR). A granitoidic magma has intruded low grade metamorphic sediments of upper Precambrium age (Pressnitzer Serie) probably during late Precambrian up to Cambrian time. Later the whole complex was deformed and metamorphosed under amphibolite facies conditions ( $\left.p \geq 4 \mathrm{kbar}, T \geq 300^{\circ} \mathrm{C}\right)$. This deformation is connected with the formation of a crystalline schistosity "sk ${ }_{1}$." The system of planes $\left(\mathrm{sk}_{1}\right)$ was deformed again into symmetric recumbent folds with southern vergency during younger, probably Variscan, times. In connection with this deformation a second crystalline schistosity " $\mathrm{sk}_{2}$ " is formed nearly parallel to the fold axes plane. The fabric evolution of quartz, studied and discussed in this paper, is a result of this second younger deformation by folding.

The studied tectonic structure is the anticlinal part of a recumbent fold with a half wavelength of about $1 \mathrm{~km}$ (Figure 1). The fold is characterized by structural features like little minor folding connected with the parallelism of $\mathbf{s k}_{\mathbf{1}}$ and $\mathbf{s k}_{\mathbf{2}}$ within the long flank of the fold, increasing intensity of the minor folding (close-folding) and increasing angle between $\mathbf{s k}_{1}$ and $\mathbf{s k}_{2}$ in the direction to the

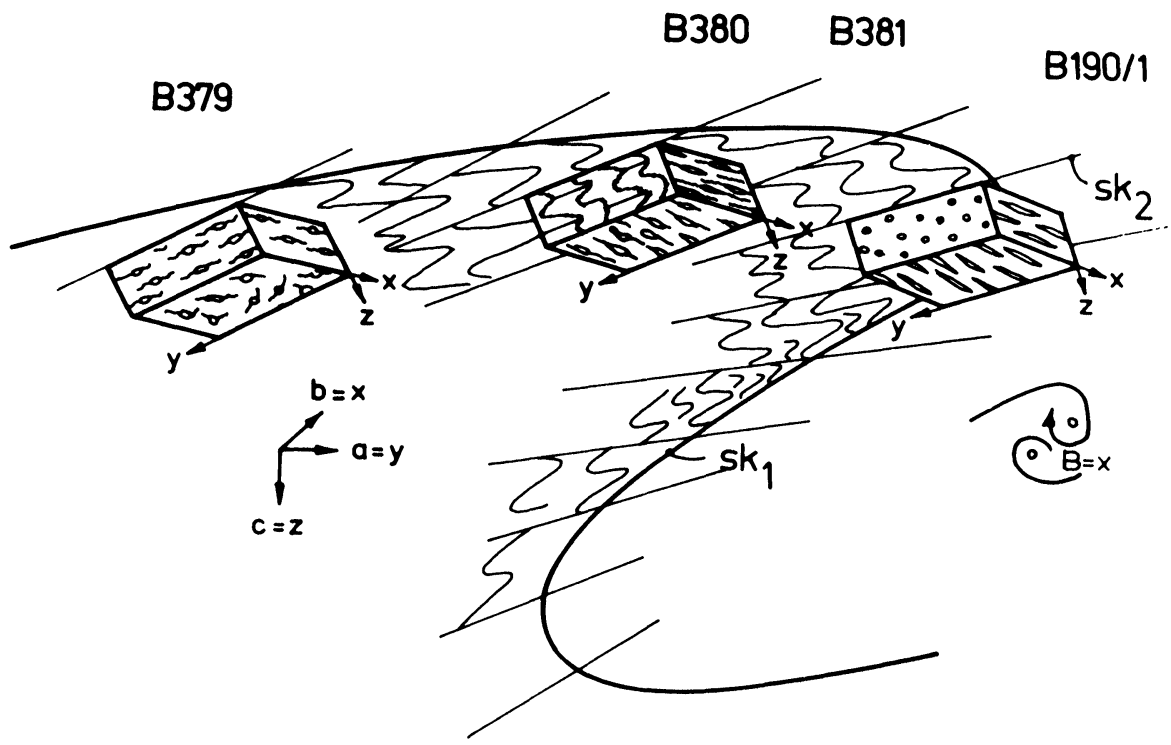

Figure 1 Structural positions of the investigated samples within the recumbent fold of $\mathbf{s k}_{1}$-planes. The tectonic coordinate system is denoted by $a b c$ and the sample system by $x y z$. 
crest of the fold (reaching $90^{\circ}$ at the crest) and pencil gneiss structure in the crest or in the inverted limb of the fold. These structural features are characteristic for deformations by folding within the upper crust, approximately down to a depth of about $5 \mathrm{~km}$. The same deformation process leading to highly symmetric fabrics ( $b$-tectonites) in the upper levels of the crust is connected with the formation of small volumes of anatectic melts along flat lying shear planes parallel to $\mathbf{s k}_{2}$ caused by frictional heating (Frischbutter, 1988) in deeper regions $(>5 \mathrm{~km})$. Therefore, the same deformation process provides high symmetric fabrics within the upper crust but fabric disordering in the lower crust, where the most intense stages of deformation have taken place.

\section{CHARACTERIZATION OF SPECIMENS}

The samples are selected to be representative for the main stages of the deformation evolution within the fold structure (Figure 1).

The most pronounced texture was expected in the specimen B190/1 (pencil gneiss) which is characterized by structural features as dominant stretching parallel to the tectonic $b$-axis and the dominance of the younger crystalline schistosity $\left(\mathbf{s k}_{2}\right)$ over the older one $\left(\mathbf{s k}_{1}\right)$. The sample represents the most intense deformation stage within the fold structure, localized between the fold crest and the inverted limb (see Drechsler et al., 1988).

The samples B380 and B381 are typical for the normal dipping flank near the crest of the recumbent fold, characterized by an angle of about $90^{\circ}$ between $\mathrm{sk}_{1}$ and $\mathbf{s k}_{2}$-planes as well as close minor folding of $\mathbf{s k}_{1}$-planes but lacking pencil structures. Their textures should be similar but somewhat weaker than in gneiss B190/1.

In the range of the flank of the fold the structural situation is determined by the parallelism of $\mathbf{s k}_{1^{-}}$and $\mathbf{s k}_{2}$-planes with low intensity of minor folding and missing pencil structures. Therefore, weak or lower symmetrical textures due to the superimposed deformation of the $\mathbf{s k}_{1}$-plane system are expected to be found in the sample B379.

The rocks under investigation are medium to coarse grained flaser gneisses of monzogranitic composition. X-ray phase analyses in conjunction with microscope modal analyses have been carried out for each sample (Table 1).

Table 1 Mineral composition of the studied specimens (in \%).

\begin{tabular}{llrrl}
\hline \multirow{5}{*}{ Minerals } & \multicolumn{4}{l}{ Specimens } \\
\cline { 2 - 5 } & $\boldsymbol{B} 379$ & $\boldsymbol{B} 380$ & $\boldsymbol{B 3 8 1}$ & $\boldsymbol{B 1 9 0 / 1}$ \\
\hline quartz & 36 & 38 & 35 & 35 \\
plagioclase & 26 & 26 & 28 & 35 \\
$K$-feldspar & 10 & 9 & 13 & 15 \\
muscovite & 17 & 17 & 14 & 10 \\
biotite & 9 & 6 & 5 & 5 \\
others & 2 & 4 & 5 & - \\
\hline
\end{tabular}


All specimens are cut as plates of $1 \mathrm{~cm}$ thickness perpendicular to the specimen $z$-axis (parallel to the tectonic $c$-axis) and an area of about $15 \times 20 \mathrm{~cm}^{2}$ parallel to the plane determined by $y$ - and $x$-axes corresponding to the tectonic $a$ - and $b$-axes respectively (see Figure 1).

\section{EXPERIMENTS}

The fabric analyses of quartz in different gneiss rocks have been carried out at the pulsed reactor IBR-2 of the JINR Dubna (Ananiev et al., 1985) by means of the neutron time-of-flight diffraction. In this technique a pulsed neutron beam is used containing neutrons of a wide wavelength spectrum. Running the flight paths $L_{1}$ from the source to the sample and $L_{2}$ from the specimen to the detector, neutrons of various wavelengths reach the counter at different times. The neutron wavelength and the time of flight are correlated by the formula (for more detail see Feldmann, 1988):

$$
\lambda=T /\left[b \cdot\left(L_{1}+L_{2}\right)\right] \quad b=2 \cdot 528 \cdot 10^{6} \mathrm{sec} / \mathrm{m}^{2}
$$

Therefore, with respect to the Bragg's law

$$
\lambda=2 d \cdot \sin \vartheta
$$

the complete diffraction pattern is recorded at constant scattering geometry simultaneously. For illustration, a TOF spectrum of quartzite is shown in Figure 2. Furthermore, by this method all pole figures under investigation may be

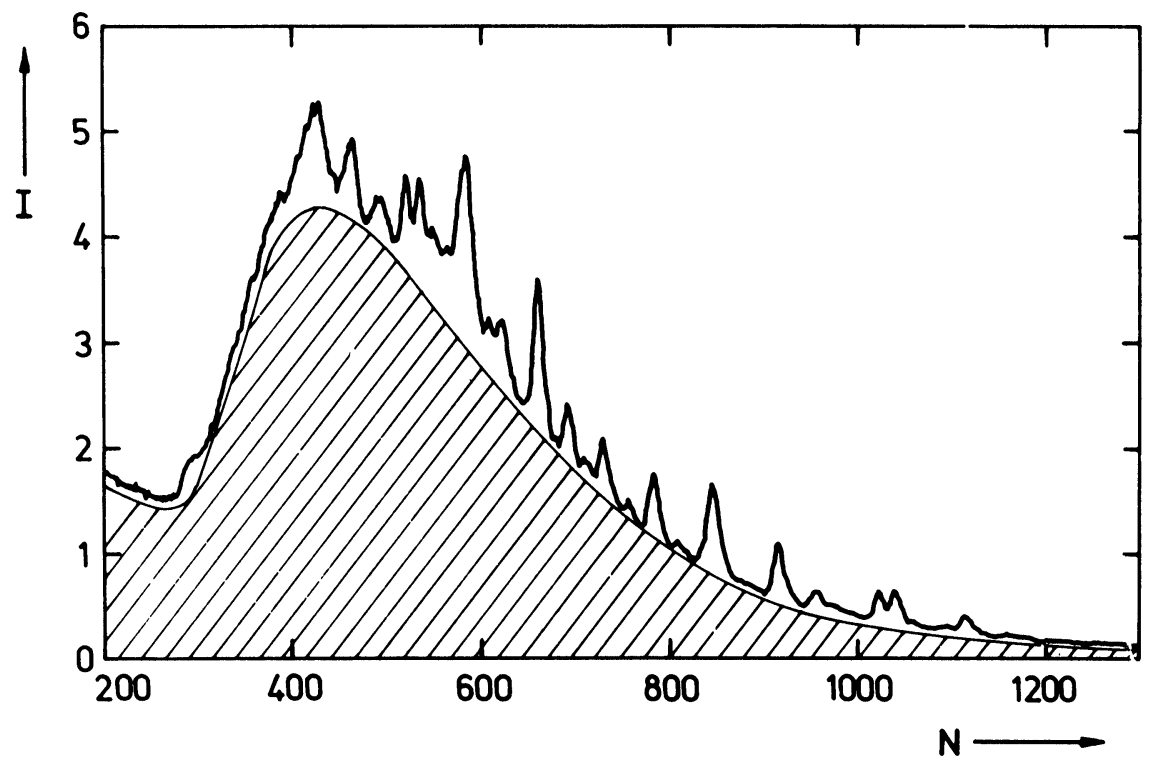

Figure 2 TOF diffraction pattern of a quartzitic rock. The shadowed area represents the incoherent background (Feldmann, 1988). 


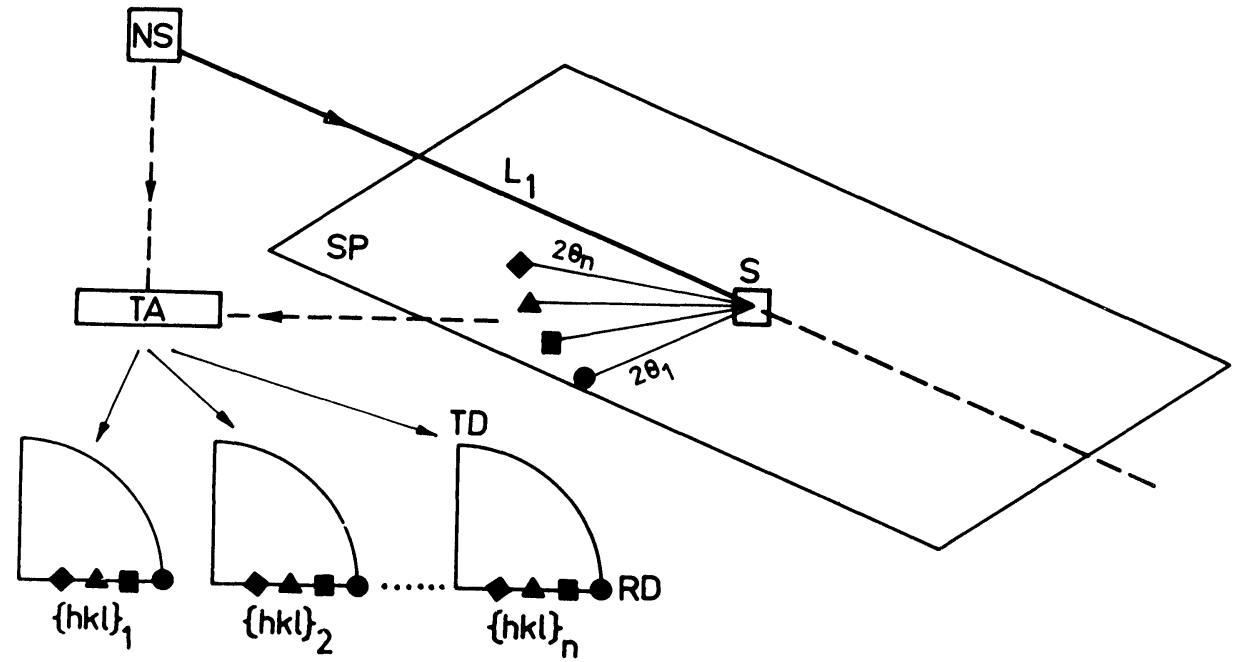

Figure 3 TOF diffraction experiment: NS-Pulsed neutron source, TA-multichannel time analyzer, $L_{1}$-flight path from the source to the sample, SP-scattering plane. $\triangle \Delta-$ Detectors, which detect the reflected beam under variant scattering angles $\theta_{i}$. In every pole figure one point at equivalent positions is recorded by one Bragg pattern simultaneously.

determined at the same time by only one scan of the texture goniometer. Figure 3 shows the schematical lay-out of a TOF experiment. To speed up the measurement two counters have been used at different scattering angles producing two points in each pole figure. The count rates of both detectors and the angle dependent resolution of a time-of flight diffractometer for a given reflection were compared by calibration measurements.

The experiments were done at the spectrometer NSWR (Ananiev et al., 1984). Its actual parameters for the investigation of specimens B379, B380 and B381 are the following:

first flight path: $\quad L_{1}=41.2 \mathrm{~m}$

second flight path: $\quad L_{2}=1.6 \mathrm{~m}$

detector positions: $\quad 2 \vartheta_{1}=80^{\circ}$

beam diameter:

\begin{tabular}{|c|c|}
\hline $2 \vartheta_{1}=80^{\circ}$ & transmission \\
\hline $2 \vartheta_{2}=100^{\circ}$ & metry \\
\hline $2 \vartheta_{1}=140^{\circ}$ & ction \\
\hline $2 \vartheta_{2}=100^{\circ}$ & geometry \\
\hline
\end{tabular}

The exposure time for one TOF spectrum is about 1 hour. By application of two detectors in transmission and reflection geometry, respectively, complete pole figures were determined rotating the triple axis goniometer around the sample normal, situated in the horizontal scattering plane (azimuth angle $\Psi$ ), and around the vertical axis (pole figure tilt angle $\Phi$ ). In this way, the specimens are not tilted around the second horizontal axis avoiding extremely enlarged irradiated sample areas. All pole figures are measured in constant- $\Phi$-circles. The steps are 
Table 2 Dependence of angle step $\Delta \Psi$ on tilt angle $\Phi$.

\begin{tabular}{lrrrrrrrrrr}
\hline$\Phi$ & $0^{\circ}$ & $10^{\circ}$ & $20^{\circ}$ & $30^{\circ}$ & $40^{\circ}$ & $50^{\circ}$ & $60^{\circ}$ & $70^{\circ}$ & $80^{\circ}$ & $90^{\circ}$ \\
$\Delta \psi$ & $36^{\circ}$ & $30^{\circ}$ & $36^{\circ}$ & $30^{\circ}$ & $24^{\circ}$ & $20^{\circ}$ & $18^{\circ}$ & $15^{\circ}$ & $10^{\circ}$ & $10^{\circ}$ \\
\hline
\end{tabular}

equidistant $\Delta \Phi=10^{\circ}$. The $\Delta \Psi$-steps are dependent on $\Phi$ (see Table 2) in the same way as for pencil gneiss (B190/1) (Drechsler et al., 1988).

The relatively large irradiated sample volume ensures a sufficient grain statistics for pole figure measurement.

\section{DATA HANDLING}

The Bragg reflection intensity at a given sample position with respect to the scattering vector is proportional to the corresponding pole figure value. These intensities have to be determined from raw TOF spectra like those shown in Figure 2 by means of a computer fit using asymmetric Gaussians with respect to the incoming neutron pulse. Firstly, the diffraction patterns have to be normalized to a wavelength independent neutron flux. The incoming spectrum from the reactor is reflected by the incoherent background in Figure 2 . For the normalization procedure a polynomial is fitted to the semi-theoretical reactor spectrum. To compare the determined pole figure points, the obtained reflection intensities are divided by the integral of the incoherent background of their own spectrum. The peak intensities and incoherent scattering component are affected in the same way by detector efficiency, fluctuations of reactor power, absorption and size of irradiated volume. Different resolution for different detectors and multiple scattering prócesses being sufficient for extreme sample positions are not taken into account by this method.

Because of several other components in the material (see Table 1) the diffraction patterns contain a large amount of peaks. Taking into account the lower lattice symmetry and the low volume fraction of the non-quartz phases, peaks of these phases appear only with small intensity in the TOF spectra (see Figure 4). Nevertheless, some influence from other components has to be expected causing a number of problems in the fit procedure due to overlapping and coincident reflections:

- There are wide regions of spectra consisting of dense sequences of peaks, where it is impossible to find reliable points for background correction. The corresponding errors are reflected mainly in the pole figure normalization. They simulate incorrect sharpness of individual pole figures and lead to mutual incompatibilities between them.

- Narrowly overlapped or even coincident reflections cannot be separated by the fit at all. If the contribution of the other minerals to a given quartz peak intensity is low and the texture of these components is assumed to be weak the corresponding errors may be supposed in a good approximation to influence only the pole figure background. Phase analyses have been used to model the TOF spectra for single phases and to select weakly contaminated quartz peaks 


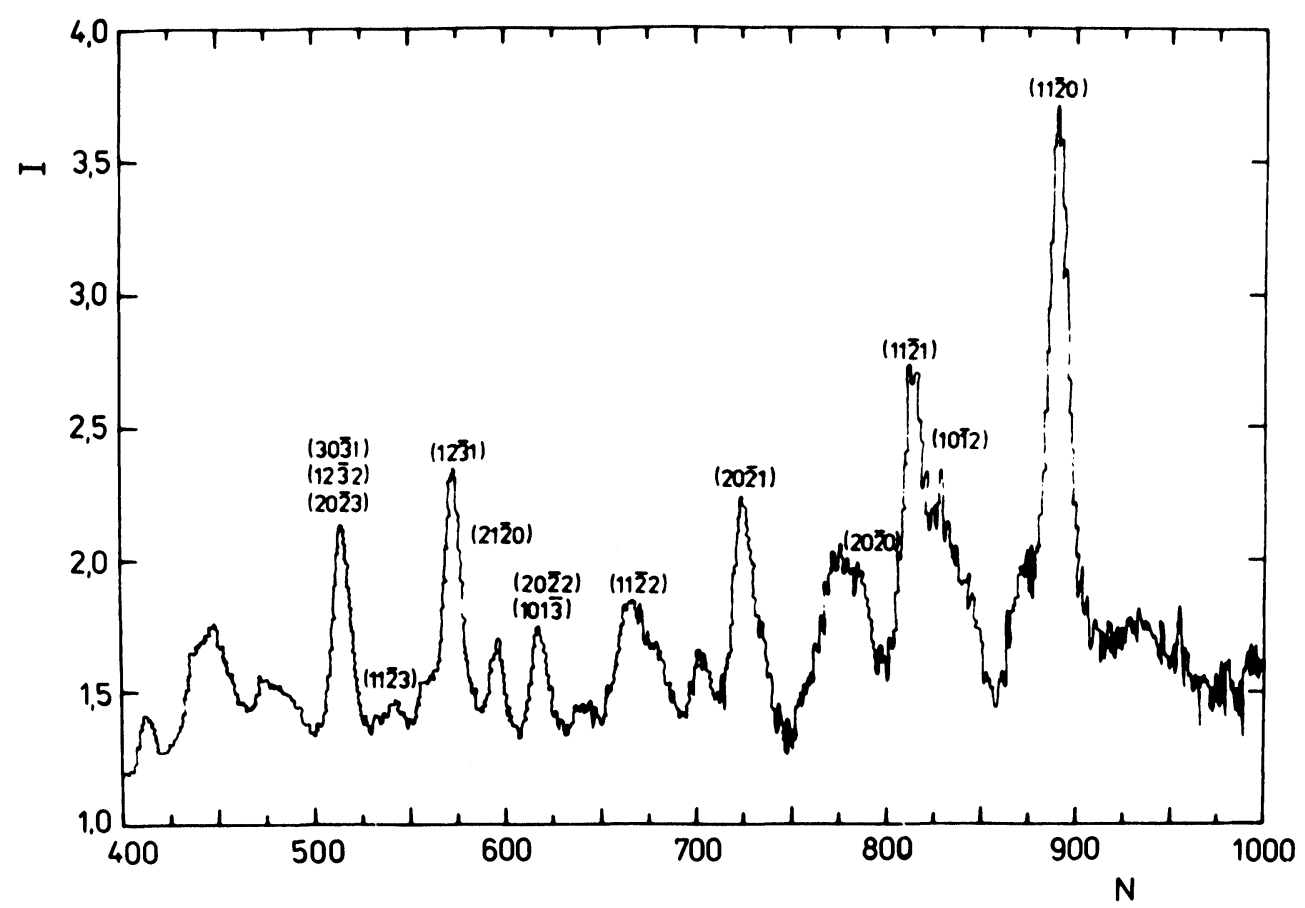

Figure 4 Diffraction pattern of pencil gneiss (B190/1) normalized to wavelength independent neutron flux (intensity versus time channel number).

for further consideration on this base. In the present fabric analyses only quartz reflections are used which are influenced by other phases to less than $30-40 \%$.

For all samples pole figure inversions and ODF calculations have been carried out by means of the spherical harmonics algorithm (Bunge, 1982) up to $l=14$ for even $l$ only. To do that, accurate and mutually consistent pole figures have to be available. Therefore, efforts were made to check the quality of pole figures and to correct them for errors like those discussed above (Feldmann et al., 1987). For all specimen the $C_{2}^{11}$-coefficients were calculated for each pole figure separately. In the case of the pencil-gneiss (specimen B190/1) a variation of the constant pole figure background has been carried out up to the approximate equality of the $C_{2}^{11}\left(h_{i}\right)$ symmetric texture coefficients which were calculated for each pole figure separately. Furthermore, the corresponding experimental and recalculated pole figures have been compared. As a result 6 pole figures were selected for texture analysis. Taking into account uncertainties of pole figures caused by the use of several detectors and by multiple scattering effects depending on constant- $\Phi$ circles for the other samples a mutual variation of these rings has been done to improve the internal and external compatibility of pole figures from one specimen. In this way, seven pole figures were selected for the texture analysis of gneisses B379, B380 and B381. In spite of all uncertainties caused by the complex structure of the samples, the quality of RP-values (Matthies, 1986) in Table 4 is quite good permitting a reliable further data handling. 
Table 3 Weight factors and lattice spacings (in $\AA$ ) for reflections contributing to pole figure intensities.

\begin{tabular}{|c|c|c|c|c|c|c|}
\hline $\begin{array}{l}\text { Reflections } \\
\quad a_{\text {hkil }} \\
\boldsymbol{d}_{\text {hkil }}\end{array}$ & $\begin{array}{c}(11 \overline{2} 0) \\
1.00 \\
2.46\end{array}$ & & & & & \\
\hline $\begin{array}{l}\text { Reflections } \\
a_{h k i l} \\
d_{h k i l}\end{array}$ & $\begin{array}{c}(10 \overline{1} 2) \\
0.10 \\
2.28\end{array}$ & $\begin{array}{c}(01 \overline{1} 2) \\
0.90 \\
2.28\end{array}$ & & & & \\
\hline $\begin{array}{c}\text { Reflections } \\
a_{h k i l} \\
d_{\text {hkil }}\end{array}$ & $\begin{array}{c}(11 \overline{2} 1) \\
1.00 \\
2.23\end{array}$ & & & & & \\
\hline $\begin{array}{l}\text { Reflections } \\
a_{\text {hkil }} \\
\boldsymbol{d}_{\text {hkil }}\end{array}$ & $\begin{array}{c}(20 \overline{2} 1) \\
0.91 \\
1.98\end{array}$ & $\begin{array}{c}(02 \overline{2} 1) \\
0.09 \\
1.98\end{array}$ & & & & \\
\hline $\begin{array}{l}\text { Reflections } \\
a_{\text {hkil }} \\
d_{\text {hkil }}\end{array}$ & $\begin{array}{c}(20 \overline{2} 2) \\
0.16 \\
1.67\end{array}$ & $\begin{array}{c}(02 \overline{2} 2) \\
0.51 \\
1.67\end{array}$ & $\begin{array}{c}(10 \overline{1} 3) \\
0.12 \\
1.66\end{array}$ & $\begin{array}{c}(01 \overline{1} 3) \\
0.21 \\
1.66\end{array}$ & & \\
\hline $\begin{array}{l}\text { Reflections } \\
a_{h k i l} \\
d_{\text {hkil }}\end{array}$ & $\begin{array}{c}(21 \overline{3} 0) \\
0.50 \\
1.61\end{array}$ & $\begin{array}{c}(12 \overline{3} 0) \\
0.50 \\
1.61\end{array}$ & & & & \\
\hline $\begin{array}{c}\text { Reflections } \\
a_{\text {hkil }} \\
\boldsymbol{d}_{\text {hkil }}\end{array}$ & $\begin{array}{c}(12 \overline{3} 1) \\
0.86 \\
1.54\end{array}$ & $\begin{array}{c}(21 \overline{3} 1) \\
0.14 \\
1.54\end{array}$ & & & & \\
\hline $\begin{array}{c}\text { Reflections } \\
a_{h k i l} \\
d_{h k i l}\end{array}$ & $\begin{array}{c}(12 \overline{3} 2) \\
0.17 \\
1.38\end{array}$ & $\begin{array}{c}(21 \overline{3} 2) \\
0.14 \\
1.38\end{array}$ & $\begin{array}{c}(20 \overline{2} 3) \\
0.32 \\
1.37\end{array}$ & $\begin{array}{c}(02 \overline{2} 3) \\
0.00 \\
1.37\end{array}$ & $\begin{array}{c}(30 \overline{3} 1) \\
0.04 \\
1.37\end{array}$ & $\begin{array}{c}(03 \overline{3} 1) \\
0.33 \\
1.37\end{array}$ \\
\hline
\end{tabular}

The series expansion formalism was applied so that to consider real and imaginary terms separately. The Euler angles $\alpha, \beta, \gamma$ have been chosen following to the notation of Matthies (1982). In this work as well as in the monograph of Bunge (1982) all relations between specimen coordinate system, Euler angles and crystal coordinate system are described in detail.

Table 4 RP-values (in \%) for the pole figures (PF) of the four specimens. Only one Miller index is given for coincident PF.

\begin{tabular}{llrrl}
\hline$P F$ & $B 379$ & $B 380$ & $B 381$ & $B 190 / 1$ \\
\hline$(11 \overline{2} 0)$ & 6.6 & 7.2 & 7.2 & 11.8 \\
$(10 \overline{1} 2)$ & 6.6 & 11.4 & 10.5 & 12.4 \\
$(11 \overline{2} 1)$ & 7.8 & 5.5 & 8.3 & 8.5 \\
$(20 \overline{2} 1)$ & 7.4 & 7.7 & 7.3 & 10.4 \\
$(20 \overline{2} 2)$ & 9.3 & 8.9 & 9.7 & \\
$(21 \overline{3} 0)$ & & & & 10.0 \\
$(12 \overline{3} 1)$ & 8.9 & 14.3 & 9.4 & 6.1 \\
$(12 \overline{3} 2)$ & 7.1 & 6.5 & 7.3 & \\
\hline
\end{tabular}


In the trigonal system powder diffraction peaks of (hkil) and (khil) type coincide completely, although they are not symmetrically equivalent. Therefore, the corresponding pole figures cannot be measured separately. They, and also pole figures determined from nonseparable strongly overlapped peaks are taken into account following the method outlined by Bunge and Wenk (1977). The weight factors $a_{h k i l}$ for the reflections contributing to the pole figures are given in Table 3. They are proportional to the squares of the neutronographic structure factors.

The structure factor of the (0003) reflection is too small for intensity determination from TOF spectra. The (1010) peak is situated in a wavelength range where neutron intensity is very low. Therefore, the basal and prism I pole figures may be obtained only by recalculation from series expansion coefficients.

\section{RESULTS AND INTERPRETATION}

The experimental pole figures used for texture analyses are shown in Figures 5-8. The initial sets of pole figures have been recalculated from $C_{l}^{\mu \nu}$ series expansion coefficients. The degree of coincidence with the experimental ones is reflected by the RP-values in Table 4. The compatibility is best for B379 and B381 specimens, which may be explained by the improved correction method described in the previous section.
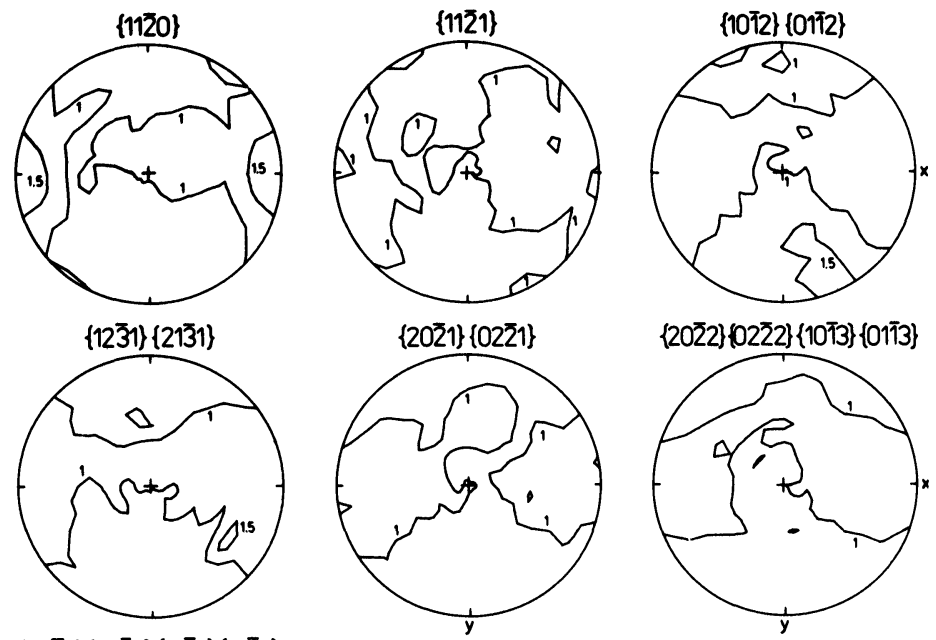

$\{20 \overline{2} 3\}\{02 \overline{2} 3\}\{12 \overline{3} 2\}\{21 \overline{3} 2\}$

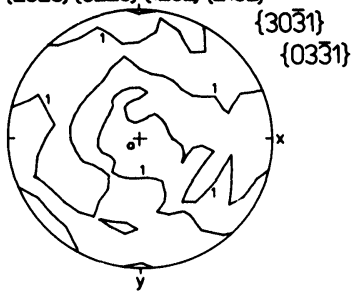

Figure 5 Experimental pole figures of sample B379. 


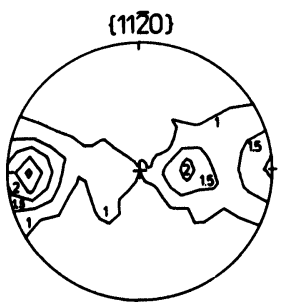

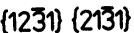

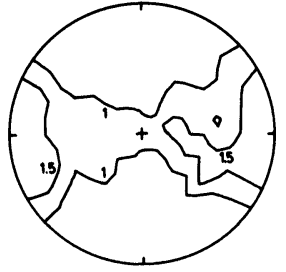

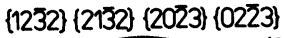

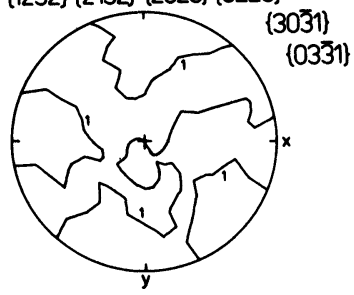

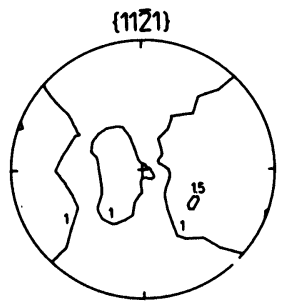

$\{20 \overline{2} 1\}\{02 \overline{2} 1\}$

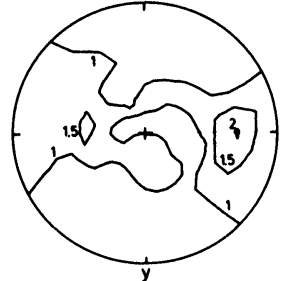

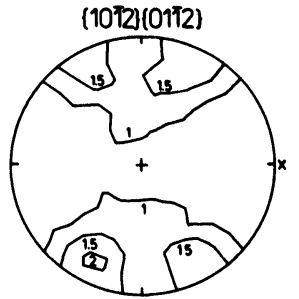

\{0113\} $\{2022\}\{0222\}\{1013\}$

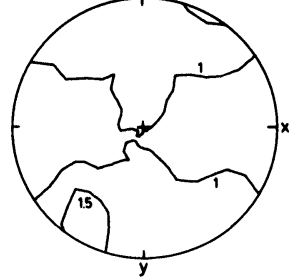

Figure 6 Experimental pole figures of sample B380.

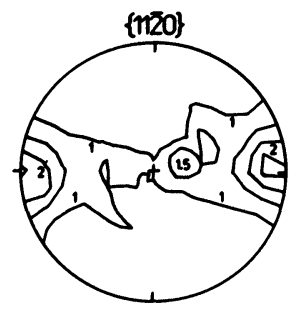

$\{12 \overline{3} 1\}\{21 \overline{3} 1\}$

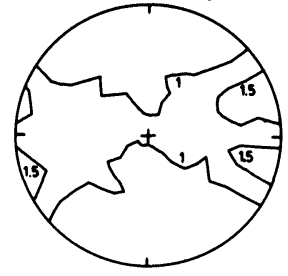

$\{12 \overline{3} 2\}\{21 \overline{3} 2\}\{20 \overline{2} 3\}\{02 \overline{2} 3\}$

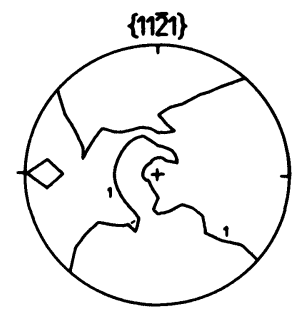

$\{2021\}\{0221\}$

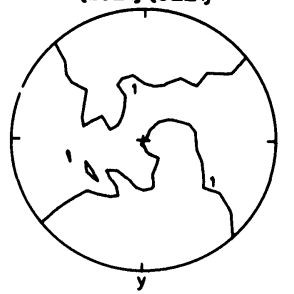

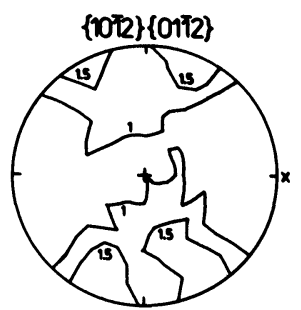

$\{0113\}\{2022\}\{0222\}\{1073\}$

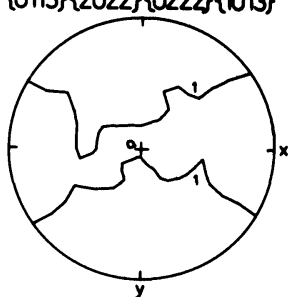

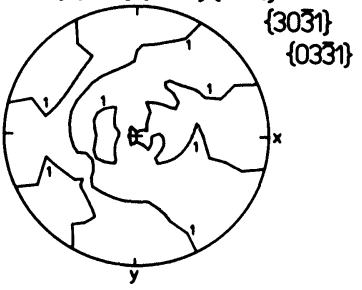

Figure 7 Experimental pole figures of sample B381. 

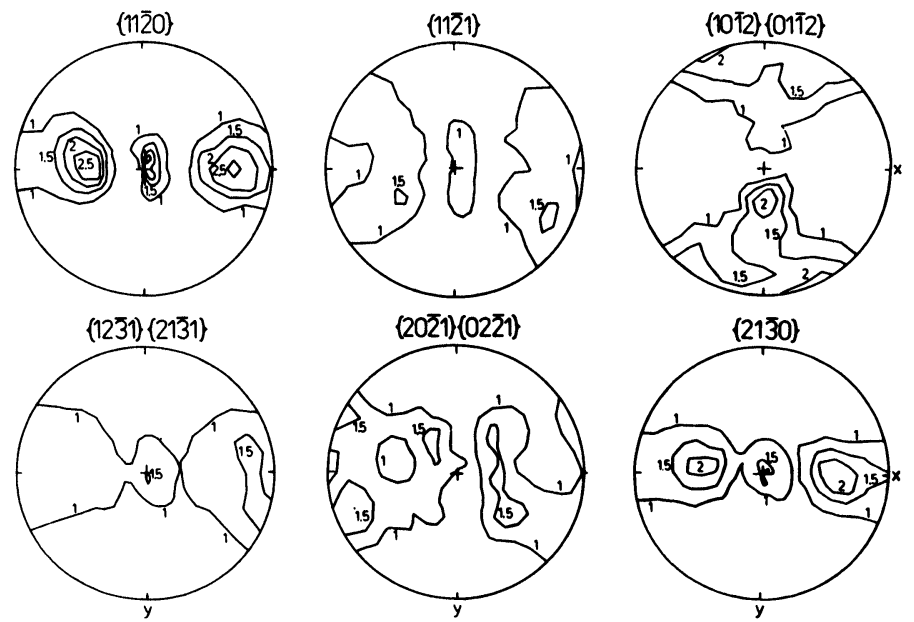

Figure 8 Experimental pole figures of sample B190/1 (Drechsler et al., 1987).

In addition to neutron texture analysis the quartz fabrics of all samples were determined within a tectonic $a c$-section for B190/1 and within a $a b$-section for all other specimens using the traditional optical method of universal stage measurements. For each sample 200 orientations have been determined. The fabric diagrams are shown in Figure 9. They may be compared with the basal pole figures in Figure 10 where the recalculated pole figures of the morphological main forms of quartz for all samples are shown.

In general, the results of fabric determination by the optical measurement of quartz $c$-axes compare well with the recalculated (0001) pole figure. In detail there are little differences: The splitting of the main maximum within the U-stage fabric diagram of pencil gneiss (B190/1) cannot be found in the recalculated (0001) pole figure. This disagreement may be explained by the relatively wide point net on the experimental pole figures and by the poor resolution resulting from the series expansion cut-off at $l=14$. Furthermore, orientations of lower density seems to be omitted in the (0001) pole figure, comparing the two types of diagrams for the sample B379, representing the lowest intensity state of deformation within the fold structure. The B379 optically determined diagram is
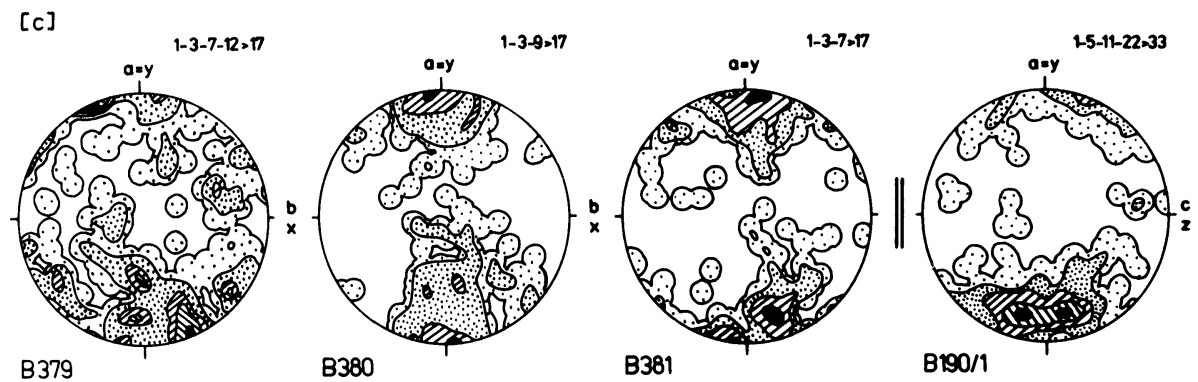

Figure 9 U-stage quartz $c$-axis fabric diagrams. 

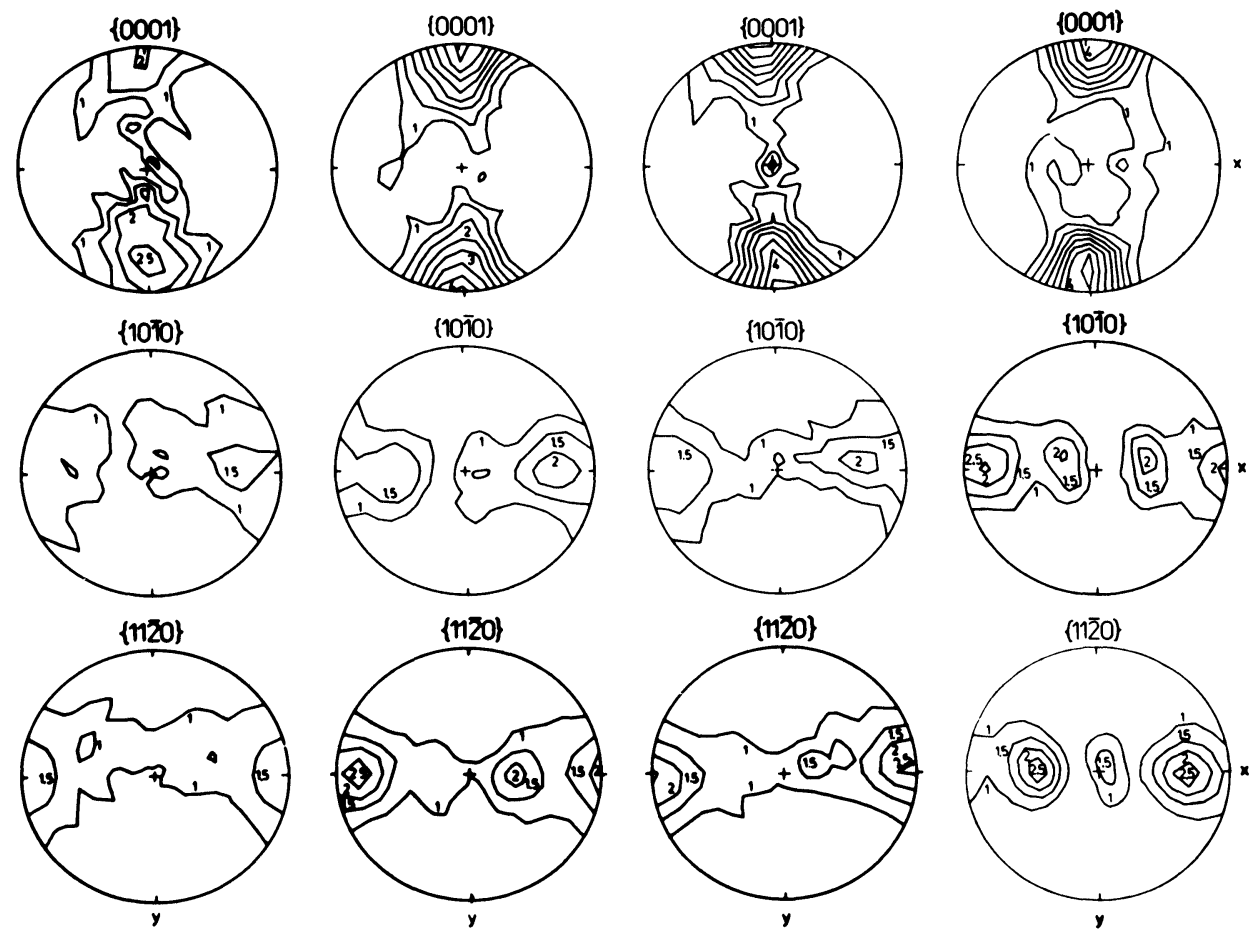

Figure 10 Pole figures of the morphological main forms of quartz, ordered with respect to increasing deformation intensity (B379, B380, B381 and B190/1 from the left).

characterized beneath the $y$-maximum of high density by an additional orientation pattern of small-circles around the cone axes $x$ perpendicular to the $y z$-plane. The opening angles are about $140^{\circ}$ and $90^{\circ}$, respectively. These small circles are formed only by weak orientation densities. In this context it is to be underlined that low density orientations are typical for naturally deformed rocks. In contrary to the optically determined fabric diagram the recalculated (0001) pole figure of sample B379 does not show these small circle pattern. They may be indicated by che distribution pattern of orientation densities $<1$. From the geological point of view these low density pattern may represent relictic, superposed fabric elements due to repeated deformation processes within the Earth's crust.

The tendency to $a c$-girdle formations observed in all recalculated basal pole figures is similar in the fabric diagrams of specimens B380 and B381. It cannot be observed in the B379 fabric diagram. The type of textures reflected by the pole figures and fabric diagrams is similar for all samples concerning the dominating maximum in the tectonic a-direction. (Maximum I or $\gamma$-law after Sander, 1930). Nevertheless, there is a distinct texture/fabric evolution with increasing intensity of deformation from sample B379 over B380/B381 to B190/1. The most important features of this evolution are (according to (0001) pole figures or $c$-axes diagrams):

- increasing sharpness of maximum I (tectonic $a$-direction), which becomes the dominating fabric orientation in pencil gneiss (B190/1) 
- disappearing small circle patterns (with low density) only by optically determined results and already from state B379 to state B380.

- decreasing tendency of ac-girdle orientation with increasing degree of deformation.

Another remarkable feature of the studied fabric evolution becomes clear in comparing the pole figures of $\{10 \overline{1} 0\}$ and $\{112 \overline{0}\}$ planes and development of inverse pole figures (Figure 11) as well. From sample B379 up to B381 the prism II $\{11 \overline{2} 0\}$ maximum is oriented in the tectonic $b$-direction. For pencil gneiss the prism I [1010] direction becomes parallel to the $b$-axis. This indicates that a fabric rotation of $30^{\circ}$ around the tectonic $a$-axis occurred in connection with the structural transition from intimate crumpling gneisses (B380, B381) to pencil gneiss (B190/1).

The inverse pole figures of the specimen $y$ direction are dominated by strong

B 379
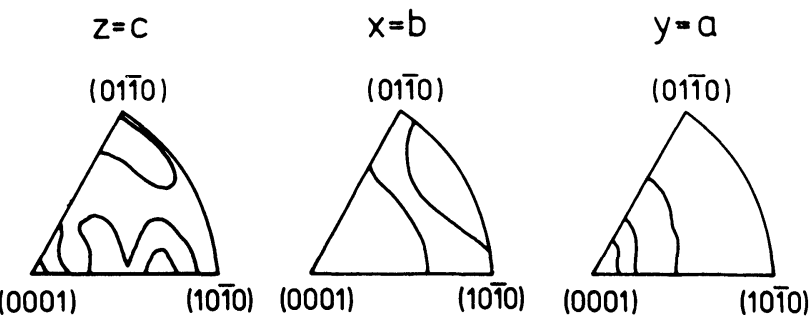

B380
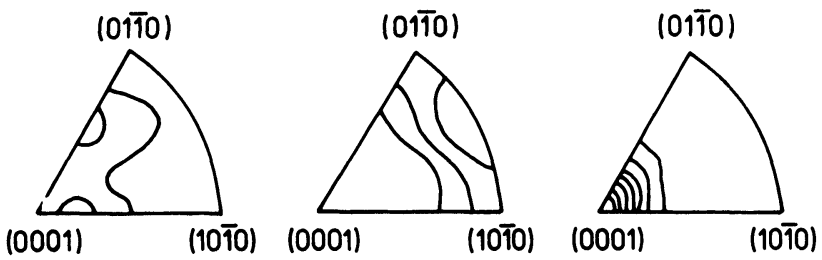

B381
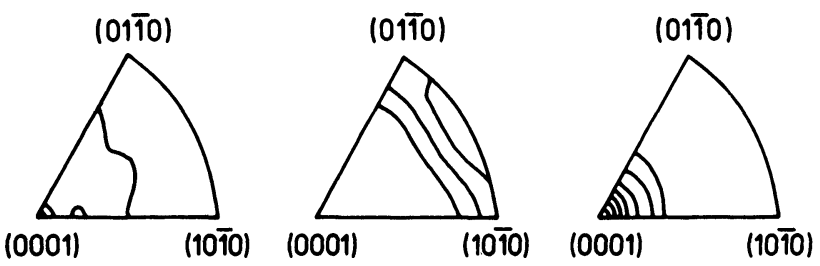

B390/1
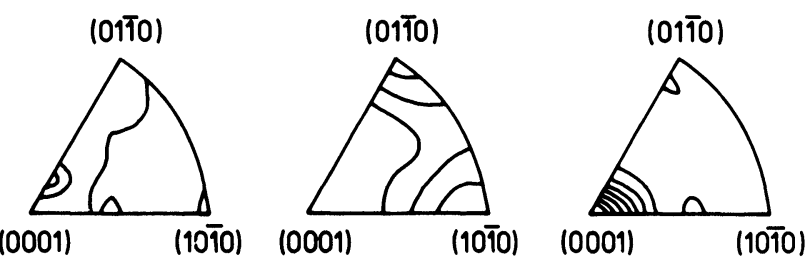

Figure 11 Inverse pole figures (from B379 to B190/1). 


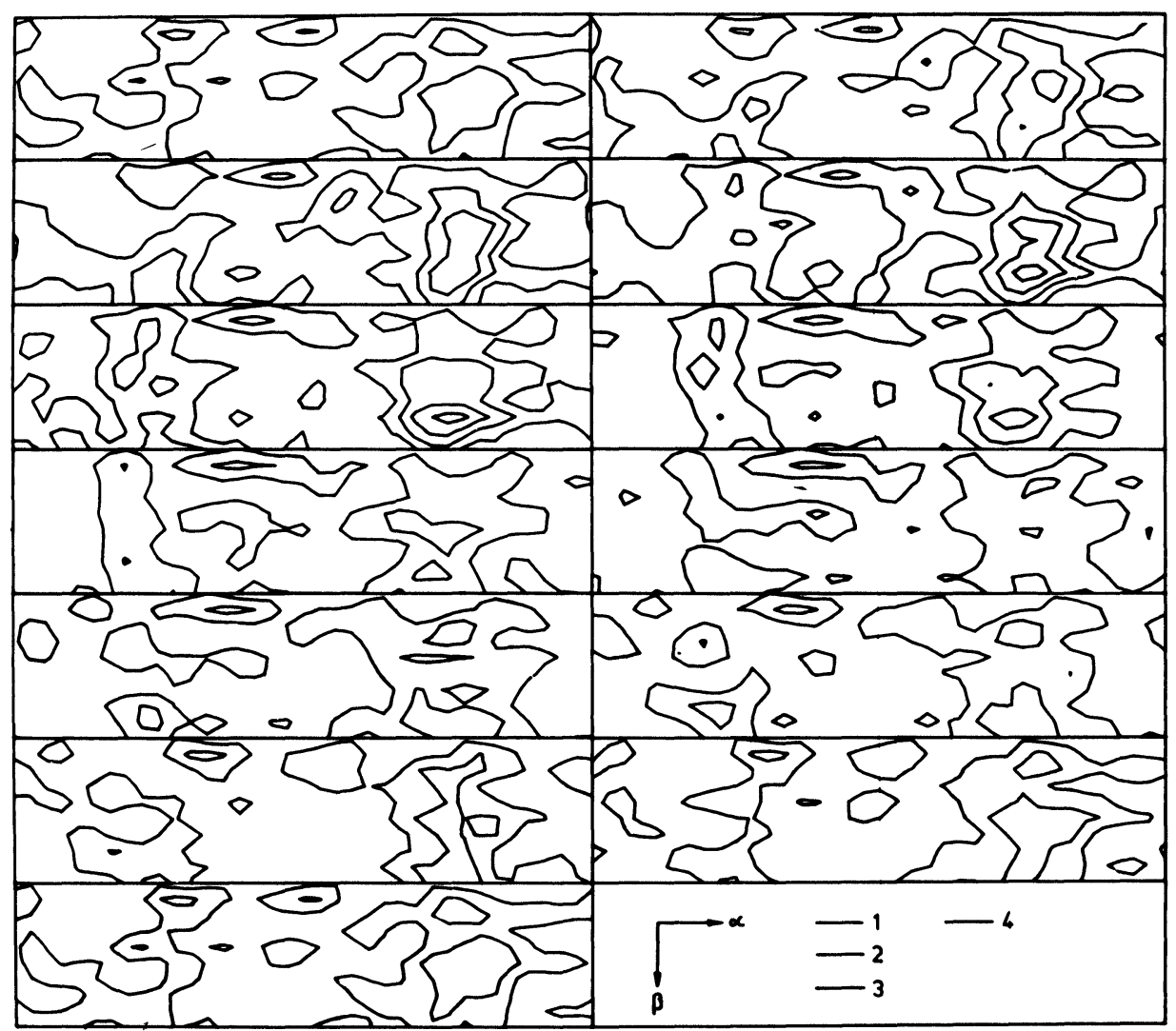

Figure 12 ODF of gneiss B379 $\left(0 \leq \alpha \leq 360^{\circ}, 0 \leq s \leq 90^{\circ}, 0 \leq \gamma \leq 120^{\circ}, \gamma=\right.$ const.-sections, $\left.\Delta \gamma=10^{\circ}\right)$.

concentration of basal planes. For the less deformed sample B379 this maximum is less pronounced.

The orientation evolution for the $z$ inverse pole figures is more complex. Sample B379 is characterized by a increased intensity of basal, bipyramid and trapezohedron planes as well. Only in the pencil gneiss fabric, prism planes acquire some importance.

The ODFs $f(\alpha, \beta, \gamma)$ of all samples (Figures 12-15) are characterized by two main maxima at $\beta_{0}=90^{\circ}$ and $\alpha_{1}=90^{\circ}$ and $\alpha_{2}=270^{\circ}$ respectively confirming the one component texture found by pole figure and inverse pole figure discussion. The maximum intensities vary from one $\gamma$-section to the next. In Figure 16 the skeleton lines of these texture components are shown where $\alpha$ and $\beta$ may differ somewhat from the given position caused by the non-optimal sample symmetry. For the gneisses B380, B381 and B190/1 two pronounced maxima are observed. The $\gamma$-distance between them is $60^{\circ}$ for $\mathrm{B} 380$ and B190/1 indicating Dauphiné twinning in the samples. For B381 this distance diminishes to about $45^{\circ}$. This decrease may be caused by the disturbed specimen symmetry once more. For 


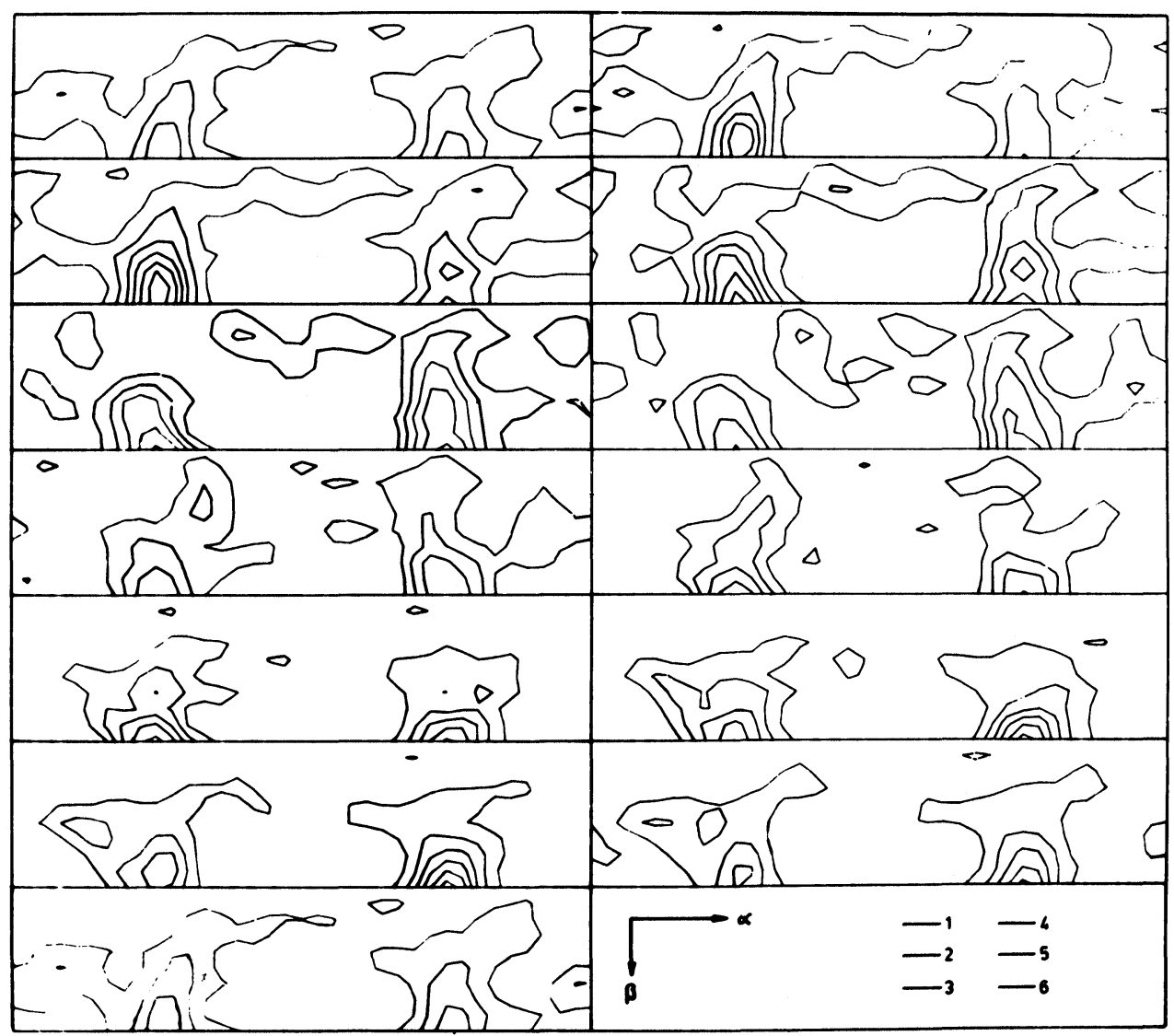

Figure 13 ODF of gneiss B380 (For angular ranges see Figure 12).

B379 only one pronounced maximum can be seen. The ODF of this gneiss is smoothed out much more than for the other rocks. Therefore, the skeleton line is doubtful at all. The fabric rotation from B380 to B190/1 is reflected by the changed positions of the main maxima in dependence on $\gamma$. The increased intensities from the maxima to $\beta=0$ at constant $\alpha$ in Figures $12-15$ refer to the various tendencies of girdle formation of the samples as discussed above.

Summarizing all results, the studied texture evolution referred by the (0001) pole figure and the inverse pole figures is characterized by two main steps:

- B379 to B380/B381: disappearing double small circle orientation pattern around $b$, tendency to $a c$-girdle formation, disappearing of trapezohedron plane contribution in the tectonic $c$-direction connected with sharper accentuation of the basal plane in $a$ - and of the prism II in $b$-direction as well.

- B380/B381 to B190/1: decreasing ac-girdle tendency in connection with the dominating sharp (split) maximum in $a$, change from prism II to prism I orientation in $b$ (fabric rotation around $a$ ) connected with prism I orientation in tectonic $c$-direction. 


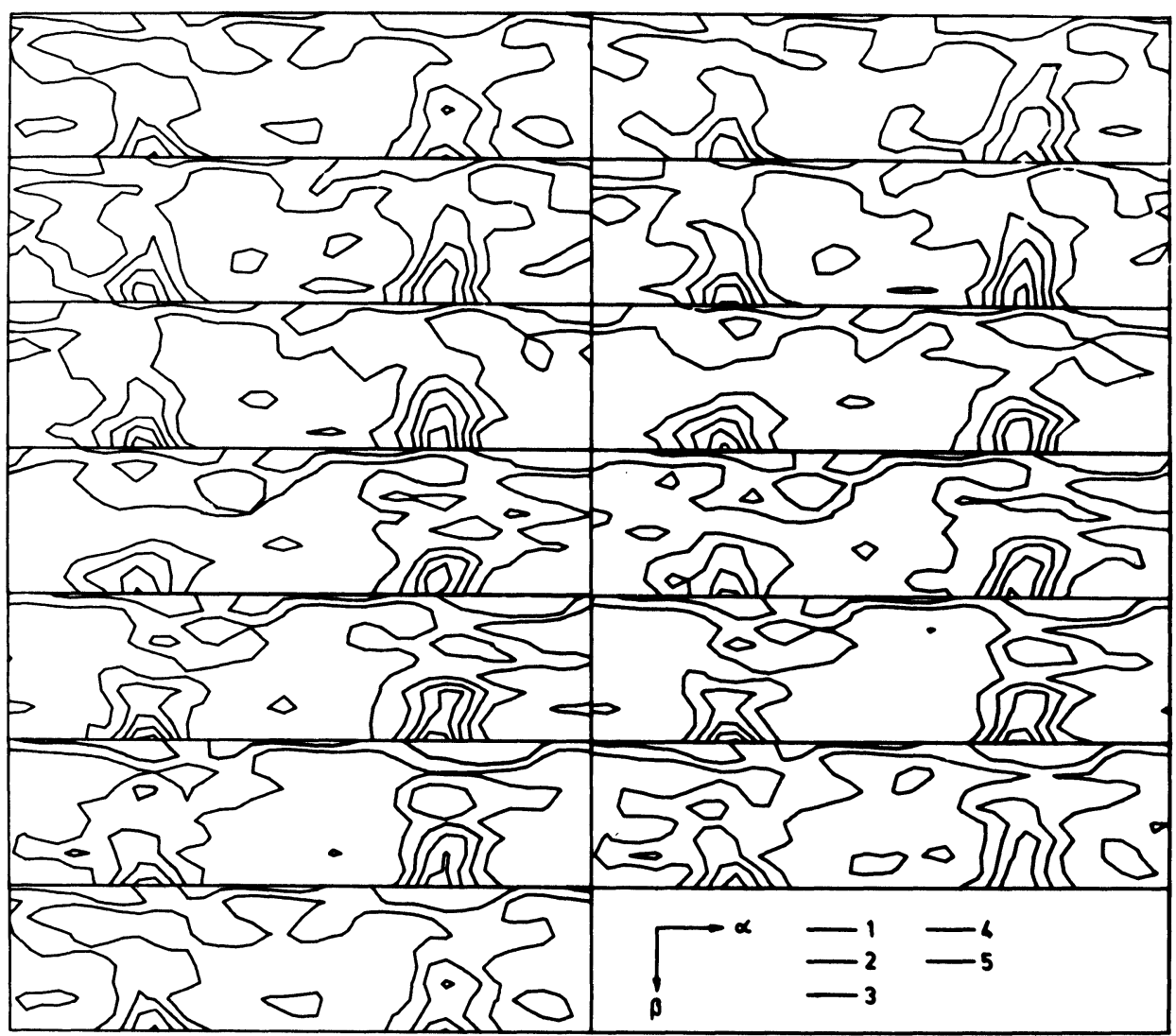

Figure 14 ODF of gneiss B381 (For angular ranges see Figure 12).

The texture investigations were combined with measurements of the anisotropy of the magnetic susceptibility $(\chi)$. The magnetic anisotropy of rocks, which is influenced first of all by the orientation of the matrix mineral content, can be easily used for a low resolution rock fabric analysis. For details on the method and geological interpretation of magnetic anisotropy data see Hrouda (1982).

In general all parts of a rock underwent a reorientation during a tectonic deformation, but in a different manner. In the investigated gneisses the magnetic anisotropy behavior is mainly caused by the biotit orientation. The trioctaedric biotits are orientated with their basal planes parallel to both of the planes of schistosity. That means a correlation between the quartz fabric and biotit orientation reflected by magnetic anisotropy parameters can be expected.

The diagrams of Figure 17 show the orientation of the main axes of the ellipsoid of anisotropy with respect to the tectonic coordinate system. The axes of maximum susceptibility are parallel to the $b$-direction. From B379 to B190/1 specimen a concentration of pole positions is observed. The evolution of the degree of anisotropy is shown by the $L-F$-diagram $\left(L=\chi_{\max } / \chi_{\text {intermed }}\right.$ and $F=\chi_{\text {intermed }}\left(\chi_{\min }\right)$, where " $L$ " represents the degree of a pencil-like form of the 


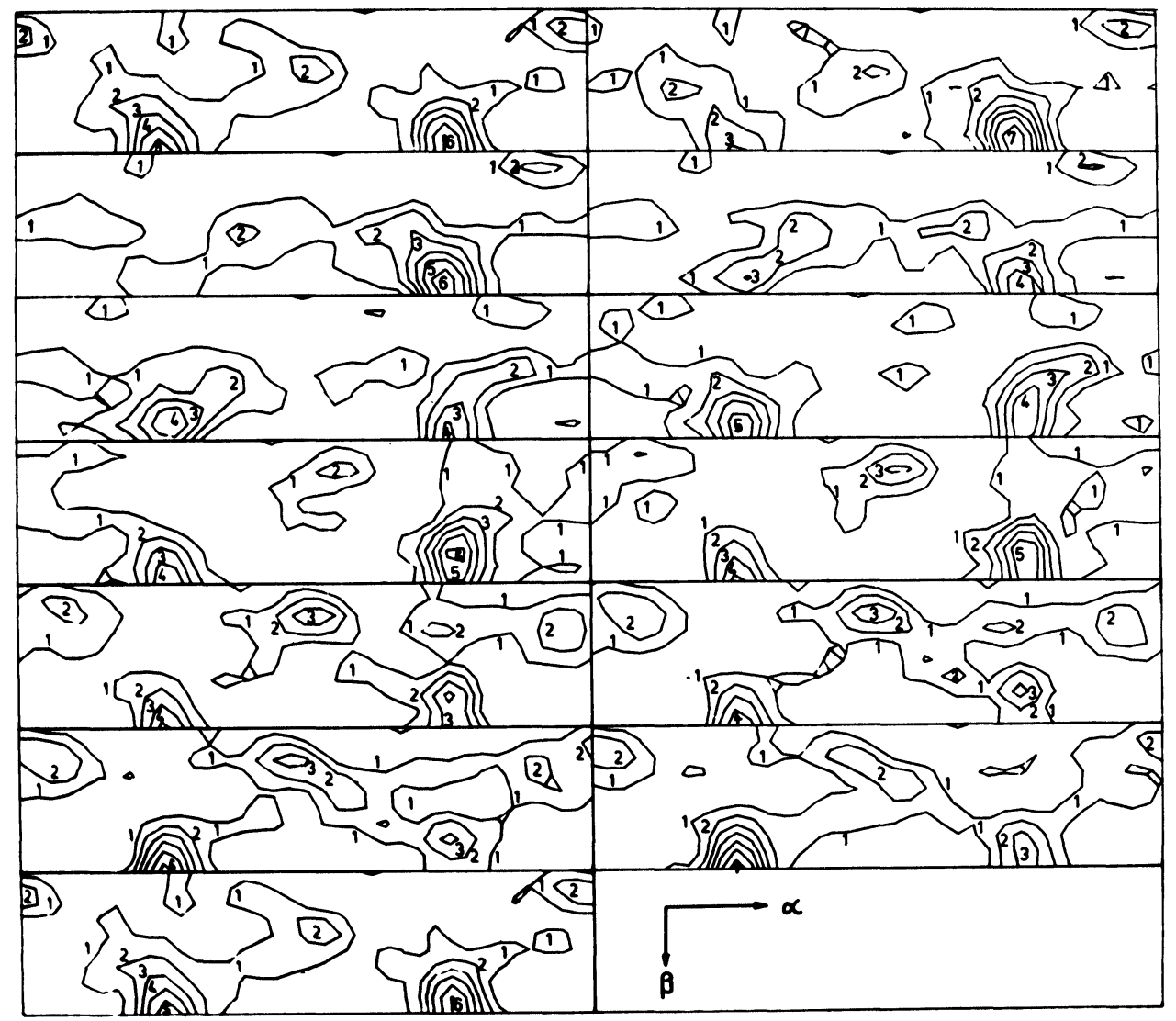

Figure 15 ODF of pencil gneiss (B190/1) (Drechsler et al., 1987) (For angular ranges see Figure 12).

ellipsoid of anisotropy, and " $F$ " the discus-like form, respectively. The information of Figure 17 can be used to characterize the texture evolution firstly of the mica component of the studied rocks. In general, the result is uniform with that one of quartz, but to a somewhat less extent: the pencil gneiss does not reach the field of dominant stretching.

The studied fabric may be interpreted as a composite texture pattern formed by an overprint of an older double small circle orientation around $[b]$ by a younger Maximum I orientation. The intermediate stages are characterized by ac-girdle orientations which may be derived from the small circles by increasing opening angles of the cones around $[b]$. According to this concept the small circles orientations are considered as a result of $s_{1}$-plane formation with respect to the tectonical evolution. The younger process of folding the $\mathbf{s k}_{1}$-plane system is reflected by $a c$-girdle orientation in connection with Maximum I fabric. In the pencil gneiss state the Maximum I type fabric becomes dominating.

With respect to the regional distribution of the types of quartz $c$-axes fabrics in the Erzgebirge Mts. small circle orientations around [b] together with Maximum I are typical for border zones between different structural levels or for discordantly 

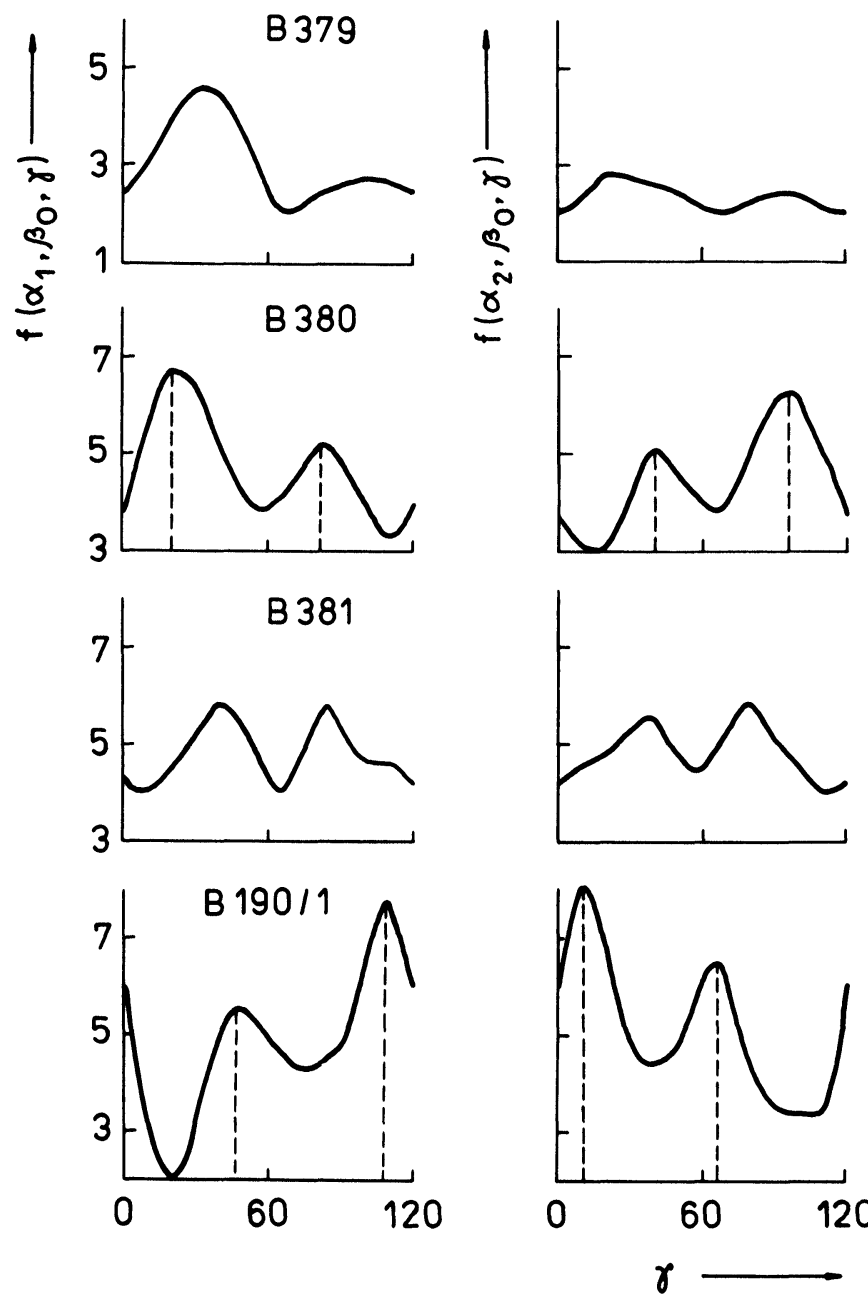

Figure 16 Skeleton lines of the main maxima of the ODFs. ( $\gamma$ in [deg.]).

different structural levels cutting shear zones such as the border zone between the Erzgebirge crystalline complex and the phyllitic unit of the Elbe syncline or the Granulite Massiv (southern GDR). The orientation type is explained by simple shear within $(a b)$ connected with external rotation (Hofmann, 1975). Furthermore, they are thought to be typical for polymineralical tectonites (Hofmann, 1974). The $a c$-girdle orientations connected with Maximum I are considered as characteristic for the upper part of the Erzgebirge crystalline complex and the external slaty surrounding the Granulite Massiv.

According to Tullis et al. (1973) basal intracrystalline slip without recrystallization leads to $c$-axes orientation parallel to $\sigma_{1}$ under conditions of $T<800^{\circ} \mathrm{C}$ and $\dot{\varepsilon}<10^{-5} \mathrm{sec}^{-1}$, where the temperature necessary for the formation of a $\sigma_{1}=a$ maximum is decreasing with increasing (geological more relevant) strain rates. 


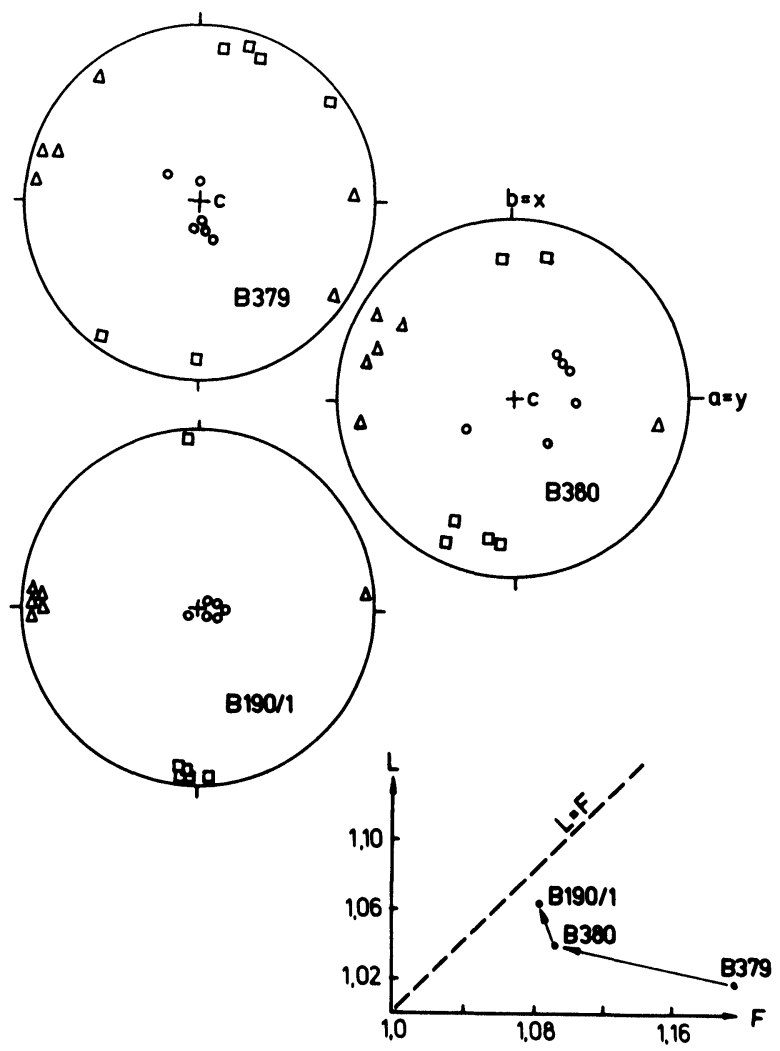

Figure 17 Anisotropy measurements of the magnetic susceptibility ( $\square-$ maximum, $\bigcirc-$ minimum, $\triangle$-intermediate susceptibility).

Increasing temperature and decreasing strain rates lead to an opening of a girdle around $\sigma_{1}=a$ just at the onset of recrystallization in Tullis, experiments. Otherwise, the formation of girdle fabrics is explained by combined operation of basal and prismatic slip, where increasing influence of prismatic slip increases the opening angle of the girdle. Green et al. (1970) reported experimental results showing $c$-axis orientations at large angles to the direction of extension comparable with $a c$-girdle orientations. Green's experiment was carried out at $T=300^{\circ}-1300^{\circ} \mathrm{C}, \dot{\varepsilon}=10^{-4}-10^{-7} \mathrm{sec}^{-1}$ and $0.1-1.2 \% \mathrm{H}_{2} \mathrm{O}$ producing significant recrystallization. There are no experimental results about double $b$-circle orientations.

Computer simulations of quartz textures using the Taylor-Bishop-Hill theory were carried out by Lister and Hobbs (1980) for three quartz models differing by the active slip systems. Our type of experimentally determined texture corresponds partly to the simulated conditions of axial extension with dominant (0001)[a] slip system, subordinate negative rhomb $[c+a]$, and minor contributing prism [a] systems. These conditions allow one to explain only the girdle and small 
circle orientations but do not give a clear evidence of single maximum textures as determined for B190/1.

Texture differences between experiments, simulations and natural samples may be due to influences such as the water content, the strain rates, effects of coexisting minerals etc.

From the geological point of view the result on the single maximum orientation of the pencil gneiss should be emphasized as typical for such petrofabrics (Vollbrecht, 1981) in comparision with other results describing small circle orientations.

\section{SUMMARY}

A recumbent fold structure of $2 \mathrm{~km}$ wavelength within an orthogneiss complex of the Erzgebirge anticlinorium is studied on four specimens representing different stages of deformation intensity. The quartz partial texture was investigated using neutron TOF diffraction and optical U-stage method as well. The results are in good agreement for both techniques and present a quartz fabric evolution, which is characterized with increasing deformation degree by the pattern as follows:

- Double small circle orientation pattern, only by optical measurement and only for the lowest stage of deformation.

- Formation of $a c$-girdle with dominant split maximum at the $a$-direction.

- Split maximum at " $a$ " connected with external rotation.

- Indication of Dauphiné twinning in the samples B380 and B190/1.

The determined quartz fabric evolution is interpreted as composed pattern with respect to the geological formation process. Furthermore, it is compared with regional fabric distribution patterns, fabric orientations produced by experiments, and texture simulations.

\section{References}

Ananiev, B. N., Betzl, M., Boede, W., Walther, K., Voronov, B. I., Goremychkin, E. A., Drechsler, L. P., Reichel, P., Urban, S., Feldmann, K., Fuentes, L. and Hoppe, U. (1984). JINR Communication P14-84-827, Dubna.

Ananiev, V. D., Kozlov, Zh. A., Luschikov, V. I., Ostanevich, Yu. M., Shabalin, E. P., Frank, I. M. (1985). Proc. Int. Conf. on Neutron Scattering in the Nineties (Juelich, 14-18 Jan 1985), Vienna, IAEA, pp. 63-73.

Bunge, H. J. (1982). Texture Analysis in Material Science, Mathematical Methods, London, Butterworth.

Bunge, H. J. and Wenk, H. R. (1977). Tectonophysics 40, 257-285.

Drechsler, L. P., Feldmann, K., Frischbutter, A. and Walther, K. (1988). JINR Preprint E14-87-345, Dubna. Textures and Microstructures, 8-9, 737-750.

Feldmann, K. (1986). Proc. Workshop on Experimental Techniques of Texture Analysis. Ed. H. J. Bunge, Oberursel, DGM Informationsgesellschaft, pp. 253-263.

Feldmann, K. Fuentes, L. and Walther, K. (1986). Proc. Workshop on Theoretical Methods of Texture Analysis. Ed. H. J. Bunge, Oberursel, DGM Informationsgesellschaft, pp. $207-214$.

Feldmann, K. (1988). Textures and Microstructures, 10, 309-323.

Frischbutter, A. (1985). Freib. Forsch. H. C390, pp. 29.

Frischbutter, A., Thomas, R. and Tauber, F. Z. geol. Wiss. 
Green, H. W., Griggs, D. T. and Christie, J. M. (1970). In: Paulitsch, P. (Ed.) Experimental and Natural Rock Deformation, Berlin. Springer-Verlag, pp. 272-335.

Hofmann, J. (1974). Freib. Forsch. H. C297, 107.

Hofmann, J. (1975). Z. geol. Wiss 3, 333-361.

Hrouda, F. (1982). Geophys. Surv. 5, pp. 37-82.

Lister, G. S. and Hobbs, B. E. (1979). J. Struct. Geol. 1, 99-115.

Matthies, S. (1982). ZfK-Preprint ZfK-480, Rossendorf.

Matthies, S. (1986). Ann. Phys. 43, 299-306.

Nicholas, A. and Poirier, J. P. (1976). Crystalline Plasticity and Solid Flow in Metamorphic Rocks. London, John Wiley and Sons.

Sander, B. (1930). Gefuegekunde der Gesteine, Vienna, Springer.

Tullis, J., Christie, J. M. and Griggs, D. T. (1973). Geol. Soc. Amer. Bull. 84, 297-314.

Vollbrecht, A. (1981). Goettinger Arb. Geol. Palaeont. 24, 122. 